\title{
The Gastrointestinal Pharmacology of Cannabinoids: Focus on Motility
}

\author{
Raquel Abalo ${ }^{\mathrm{a}}$ Gema Vera ${ }^{\mathrm{a}}$ Ana Esther López-Pérez ${ }^{\mathrm{b}}$ \\ María Martínez-Villaluenga ${ }^{a}$ María Isabel Martín-Fontelles ${ }^{a}$ \\ a Departamento de Farmacología y Nutrición, Facultad de Ciencias de la Salud, Universidad Rey Juan Carlos, \\ Alcorcón, y ${ }^{b}$ Unidad del Dolor, Servicio de Anestesia, Hospital General Universitario Gregorio Marañón, \\ Madrid, España
}

\section{Key Words}

Cannabinoid - Gut - Gastrointestinal motility • lleus • Irritable bowel disease - Gastro-oesophageal reflux • Nausea $\cdot$ Emesis

\begin{abstract}
The marijuana plant Cannabis sp. and its derivatives and analogues, known as cannabinoids (CBs), induce many effects throughout the whole body. Herein we briefly review the gastrointestinal (Gl) pharmacology of $\mathrm{CBs}$, with special focus on motor function. Some drugs are available to treat nausea and emesis, and evidences in humans and animal models suggest that other $\mathrm{Gl}$ motility alterations (gastro-oesophageal reflux, inflammatory bowel conditions or paralytic ileus) might benefit from modifications of the $\mathrm{CB}$ tone throughout the gut. However, central and peripheral (including Gl) side effects may occur upon acute and chronic $C B$ administration. Hopefully, the ongoing worldwide intense research on CBs will soon provide new, safer CB-based medicines.
\end{abstract}

Copyright $\odot 2012$ S. Karger AG, Basel

\section{The Endocannabinoid System in the Gastrointestinal Tract}

Preparations derived from the marijuana plant Cannabis sp. have been traditionally used to treat a variety of gastrointestinal (GI) conditions that range from enteric infections and inflammatory conditions to disorders of motility, emesis and abdominal pain [1]. In addition to its major psycho-active compound, $\Delta^{9}$-tetrahydrocannabinol (THC), which accounts for its millenary recreational use, the plant contains other cannabinoids (CBs) with fewer, if any, psychotropic actions, which may contribute to its pharmacology. These include cannabidiol (CBD), $\Delta^{9}$-tetrahydocannabivarin, cannabichromene, cannabigerol, cannabidivarin and acidic CBs such as $\Delta^{9}$-tetrahydrocannabinolic acid and cannabidiolic acid [2].

Currently, the following CB-based medications are available [3]:

- Sativex (GW Pharmaceuticals), as a sublingual oromucosal spray containing THC and CBD, indicated for pain and spasticity in patients with multiple sclerosis;

- Marinol (Solvay Pharmaceuticals, Belgium), as an oral capsule containing dronabinol (a synthetic THC), indicated as an appetite stimulant and anti-emetic drug;

Departamento de Farmacología y Nutrición

Facultad de Ciencias de la Salud, Universidad Rey Juan Carlos

Avda. de Atenas s/n, ES-28922 Alcorcón (Spain)

Tel. +34 9148888 54, E-Mail raquel.abalo@urjc.es 
- Cesamet (Valeant Pharmaceuticals International), as an oral capsule containing nabilone (a synthetic THC analog), indicated for patients with chemotherapy-induced nausea and vomiting.

Studies on the molecular mechanism of action of THC allowed the identification of an endogenous signalling system, known as the endocannabinoid system [4]. The main components of this system are $[5,6]$ :

- the CB1 and CB2 receptors, which are the classical receptors for all types of $\mathrm{CB}$ agonists (endocannabinoids, phytocannabinoids and synthetic $\mathrm{CBs}$ );

- the endogenous CB ligands, $\mathrm{N}$-arachidonoylethanolamine (anandamide) and 2-arachidonylglycerol (2$A G)$, which are part of a larger family of lipid mediators synthesized from common precursors (mainly arachidonic acid) and active on $\mathrm{CB}$ and other receptors;

- the biosynthetic and metabolic (degradative) pathways for the endocannabinoids and related lipid mediators;

- a hypothetical membrane transporter [7], not yet cloned and whose existence is under discussion [8].

The pharmacology of CBs and their potential therapeutic targets in the GI tract have been extensively described in a number of reviews [3,9-12].

CB1 receptors are located on nerve fibres and synapses throughout the gut wall, but with the highest density in the myenteric and submucosal plexuses of the enteric nervous system [9]. In contrast, CB2 receptors are less frequent but are overexpressed under inflammatory conditions [13]. Additional receptors upon which the CBs and related lipids might exert different GI effects are transient receptor potential vanilloid 1 (TRPV1), peroxisome proliferator-activated receptor $\alpha$, GRP55 or GRP119 $[3,11]$.

Anandamide and 2-AG are synthesized 'on demand' from membrane lipids [5]. Inactivation of anandamide and 2-AG occurs intracellularly. The dominant enzyme responsible for the hydrolysis of anandamide (and other $\mathrm{N}$-acyl-ethanolamines) is fatty acid amide hydrolase (FAAH). FAAH is localized to cell bodies in the myenteric plexus throughout the whole gut [9]. Although FAAH also inactivates 2-AG, mono-acylglycerol lipase (MAGL) is its principal hydrolase. MAGL mRNA and protein are distributed in the muscle and mucosal layers of the ileum and in the duodenum, proximal colon and distal colon. MAGL expression was found in most nerve cell bodies and also in nerve fibres of the enteric nervous system [14]. Neither CB receptors nor MAGL have been found in nitric oxide synthase-containing neurons $[9,14]$.
CBs in the gut mediate gastroprotection and modulate gastric secretion, GI motility, ion transport, visceral sensation and cell proliferation [11], as well as other effects in the oral cavity, including modifications in salivation [15]. In addition, evidence is emerging that exogenous and endogenous CBs have an important role in GI physiopathology, such as GI inflammation [16]. Figure 1 summarizes the main effects induced by CBs in the GI tract.

The present review will describe the effects of CBs (and CB-related ligands) on GI motility and their potential therapeutic usefulness as motility modifiers in different conditions, with a special focus on experimental findings.

\section{Cannabinoids Reduce Gastrointestinal Motor Function}

In agreement with the effects traditionally recognized for the CBs in the GI tract, early reports showed that THC reduced faecal bolus counts in open-field experiments [17] and decreased intestinal transit [18]. These effects have been confirmed for plant-derived, endogenous and synthetic CB receptor agonists, which reduced gastric emptying, upper GI transit and colonic propulsion in rodents (reviewed in Aviello et al. [10] and Izzo and Sharkey [11]). In addition, it was soon found that THC inhibited electrically induced cholinergic contractions of the guinea pig ileum $[19,20]$. These observations were also extended to additional preparations and $\mathrm{CB}$ analogues, and different CBs were shown to reduce electrically induced contractions in the mouse or rat stomach, guinea pig and human ileum, as well as human colon (reviewed in Izzo and Sharkey [11] and Pertwee [21]).

These CB effects are due to a presynaptic inhibition of excitatory neurotransmitter (acetylcholine, substance $\mathrm{P}$ ) release mediated by activation of the CB1 receptor, which is found on the myenteric neurones, as already suggested by early in vitro functional assays (isolated tissues) [20, 22], electrophysiological recordings [23] and immunohistochemical studies [24].

The $\mathrm{CB}$ antipropulsive actions are likely the result from a reduction of peristalsis throughout the gut $[1,21]$. In fact, all the components of the peristaltic reflex are affected, at least in the rat colon, in which CBs inhibited the ascending contraction and concomitant substance $\mathrm{P}$ release, the descending relaxation and concomitant vasoactive intestinal peptide release, and the sensory limb and concomitant calcitonin gene-related peptide release via CB1 receptor activation [25]. 


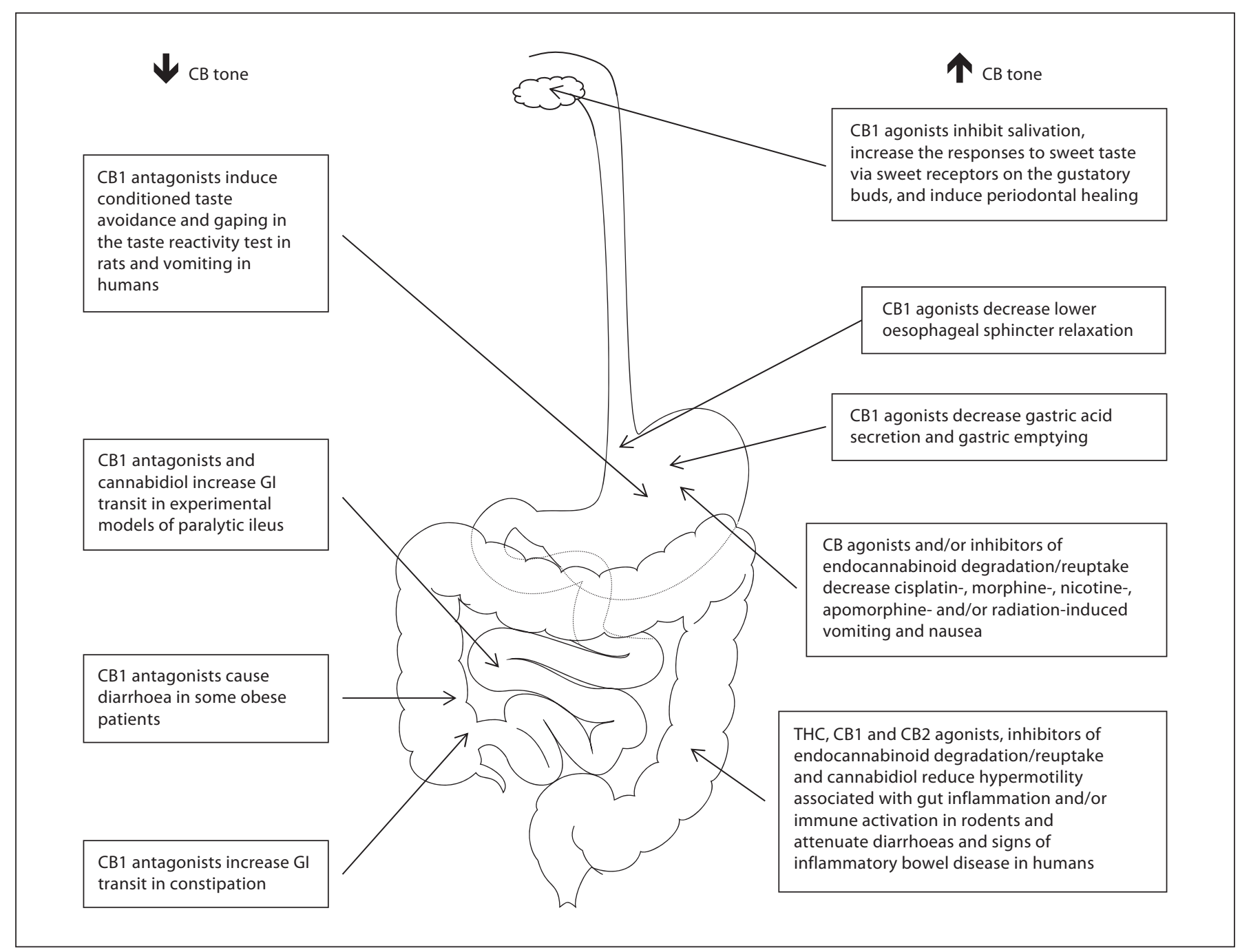

Fig. 1. $\mathrm{CB}$ effects throughout the gut. The increase or decrease in $\mathrm{CB}$ tone exerts the pharmacological effects indicated in the figure. See text for references.

It has been suggested that gut motility is under tonic control by the release of endocannabinoids [26] and that myenteric $\mathrm{CB} 1$ receptors constitute a physiological 'brake' along the GI tract. Indeed, it has been shown in primary cultures of the myenteric plexus that $\mathrm{CB} 1$ receptor antagonists increased spontaneous neural network activity in both excitatory and inhibitory neurons, whereas methanandamide (a synthetic anandamide analogue) and FAAH inhibition reduced spontaneous neural network activity [27]. CB1 receptors were shown to regulate the probability of vesicle release at the terminals of enteric nerves [27]. Furthermore, in CB1 receptor-deficient mice, a greater proportion of myenteric neurones received spontaneous fast excitatory postsynaptic poten- tials and responded more intensely to depolarization than neurones from wild-type animals [28]. This facilitation of synaptic transmission in CB1-knockout mice was mediated by an activity-dependent liberation of a retrograde purine messenger [28].

The effects of chronic administration of CBs on GI motor function have deserved less attention. This is important, since cannabinoids are being proposed for the treatment of different chronic diseases (including those affecting the gut [3]). Recently, we have analysed the in vivo effects of the non-selective CB agonist WIN 55,212-2 (WIN) in the rat after different patterns of chronic (repeated) administration, by means of non-invasive, radiographic techniques (fig. 2). First, we confirmed that WIN 


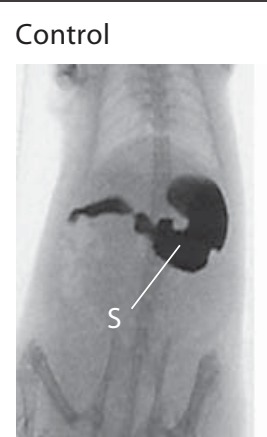

WIN $5 \mathrm{mg} / \mathrm{kg}$

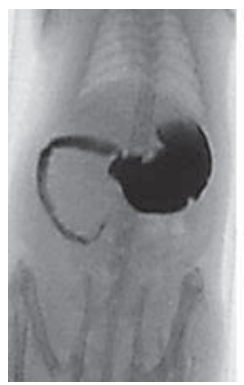

$\mathrm{Oh}$
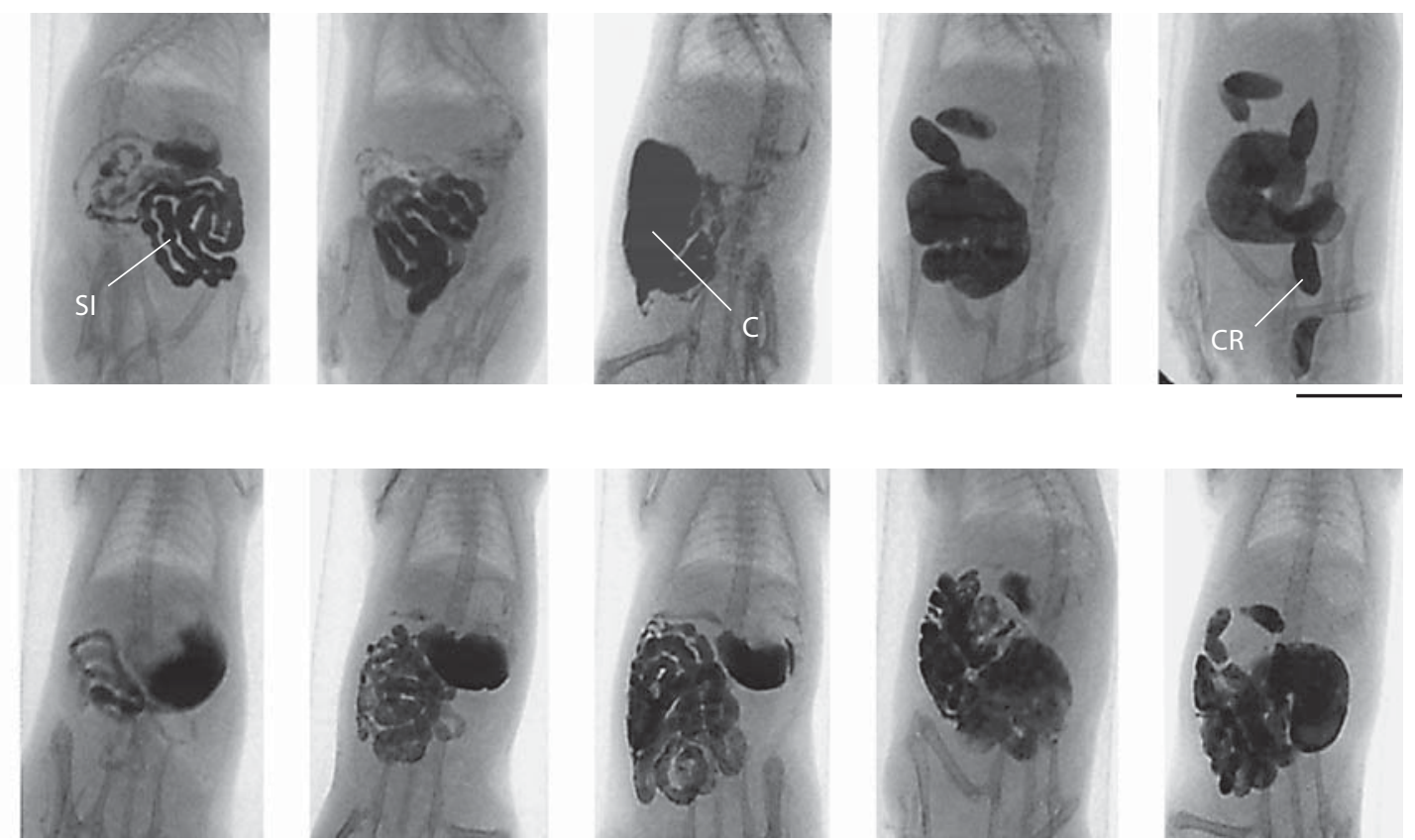

$1 \mathrm{~h}$

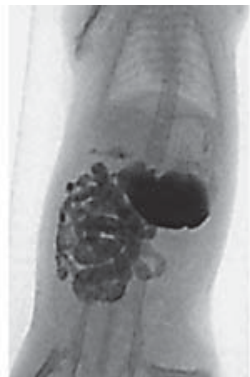

$2 \mathrm{~h}$

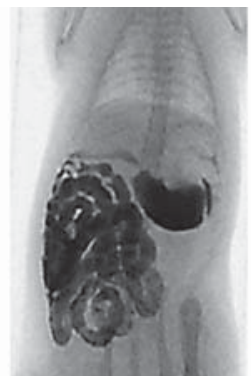

$4 \mathrm{~h}$

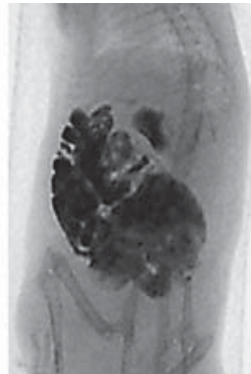

$6 \mathrm{~h}$

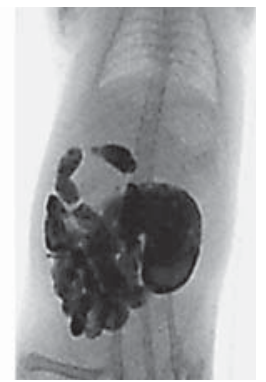

$8 \mathrm{~h}$

a

Time after contrast

Fig. 2. Radiographic analysis of GI motor function in the rat. a Two representative series of X-rays corresponding to 2 rats treated with vehicle (control) or with the CB agonist WIN 55,212-2 (WIN), respectively. WIN (5 $\mathrm{mg} / \mathrm{kg}$, a relatively high dose) and vehicle were injected intraperitoneally, and immediately afterwards $2.5 \mathrm{ml}$ of a suspension of barium sulphate $(2 \mathrm{~g} / \mathrm{ml})$ were administered per os. Plain facial images of the GI tract were obtained using a Digital X-Ray apparatus (Siemens; 60 kV, 7 mA) and captured with NPG Real DVD Studio II software. Exposure time was adjusted to $0.06 \mathrm{~s}$. Rats were briefly immobilized in the prone position by placing them inside adjustable hand-made transparent plastic tubes. No anaesthesia was applied to avoid GI motility alterations. Images were obtained at different times $(0-$ $8 \mathrm{~h}$ ) after contrast administration. $\mathrm{S}=$ Stomach; $\mathrm{SI}=$ small intestine; $\mathrm{C}=$ caecum; $\mathrm{CR}=$ colorectum - notice the faecal pellets within this region. Scale bar $=32 \mathrm{~mm}$. dose-dependently reduces motility throughout the gut and that this effect is sensitive to CB1 blockade [29, 30], although the effect of WIN in the stomach might involve an additional non-identified receptor [30]. Second, we analysed the effects of daily (14 intraperitoneal injections, 1/day) and intermittent (4 intraperitoneal injections, 1/ week) administration. Upon daily administration, tolerance developed to WIN effects in the small and large intestine, but not in the stomach [29]. However, upon intermittent administration, the gastric effect of WIN was enhanced to the point that it did not allow for a proper separate analysis of motility in the small and large intestines [31]. Therefore, the stomach shows peculiar responses to $\mathrm{CB}$ acute and chronic treatments.

The radiographic techniques have thus provided new data on the effect of CBs on gastric motor function. The radiographic study of the effect of CBs on the small intes- tine is more difficult due to the intense 'folding' of this organ within the abdominal cavity. However, the contractile pattern of the small intestine (i.e. peristaltic or mixing contractions) can be analysed fluoroscopically in situ [32]. In a pilot experiment, we have confirmed that in a CB-treated rat, the frequency and strength of small intestinal contractions are highly reduced in comparison with what is found in a vehicle-treated control rat (online suppl. material; for all online suppl. material, see www. karger.com/doi/10.1159/000339072). The application of this technique, which allows for in situ observation of gut movement, might soon provide new data (with the aid of spatio-temporal analysis, currently under development in collaboration with GW Hennig, University of Nevada, Reno) on the acute and chronic effects of CBs throughout the whole GI tract, in both control animals and pathological models. 


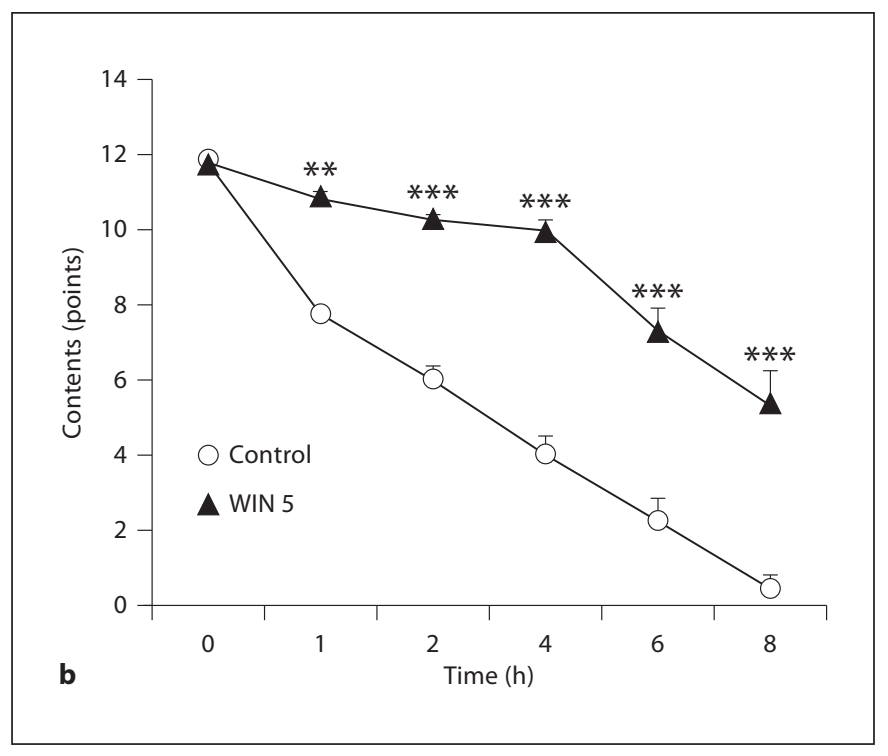

Fig. 2. Radiographic analysis of GI motor function in the rat. b Analysis of the effect of WIN on gastric emptying. GI motor function is semiquantitatively determined from the X-ray images as described before [29-31]. In this example, only the analysis for the stomach is shown. Briefly, a compounded value is assigned to the different GI regions. In this analysis, the following parameters are considered for each GI region: percentage of the GI region filled with contrast ( $0-4$ points); intensity of contrast ( $0-4$ points); homogeneity of contrast (0-2 points), and sharpness of the GI region profile ( $0-2$ points). Each of these parameters is scored, and a sum ( $0-12$ points) is made. Data represent means

\section{CB Effects on Altered GI Motility}

\section{Gastro-Oesophageal Reflux}

The lower oesophageal sphincter controls the passage of a swallowed bolus to the stomach and prevents the reflux of gastric contents into the oesophagus. Transient lower oesophageal sphincter relaxations are the predominant mechanisms underlying gastro-oesophageal reflux. They are mediated by a vagovagal reflex, which can be blocked, among others, by CB1 receptors [33]. As recently shown, both $\mathrm{CB} 1$ and $\mathrm{CB} 2$ receptors are abundantly expressed in humans along the vagovagal neural pathway involved in the triggering of transient lower oesophageal sphincter relaxations [34]. Interestingly, activation of $\mathrm{CB} 2$ receptors reduced microvascular leakage and bronchoconstriction when acid was instilled in a guinea pig model of gastro-oesophageal reflux [35]. Therefore, an increased CB tone could be useful for the treatment of gastro-oesophageal reflux as an adjunct therapy with acid inhibition [3].

Cannabinoids and Gastrointestinal Motility

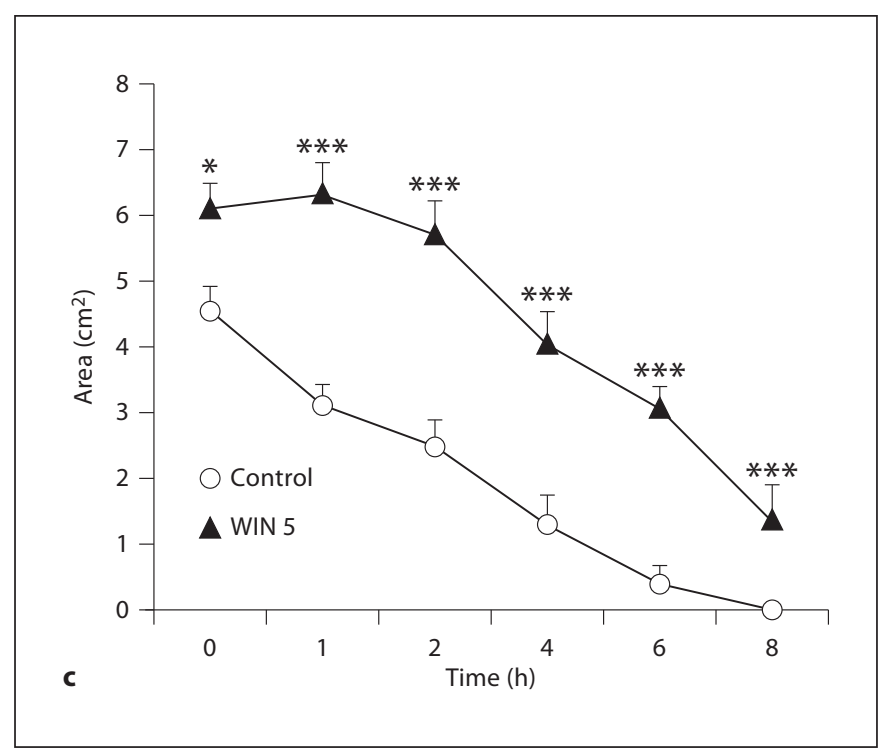

\pm SEM for motor function in the stomach of rats treated with vehicle (control, white circles) or WIN (5 mg/kg, i.p., dark triangles). c Analysis of the effect of WIN on the size of the stomach. This analysis is carried out with the aid of an image analysis system (Image J 1.38 for Windows, National Institute of Health, USA, free software: http://rsb.info.nih.gov/ij/). Data represent means \pm SEM for stomach size of rats treated with vehicle (control, white circles) or WIN (5 mg/kg, i.p., dark triangles); $\mathrm{n} \geq 8$, each group. ${ }^{*} \mathrm{p}<0.05,{ }^{* *} \mathrm{p}<0.01,{ }^{* * *} \mathrm{p}<0.001$ versus control (two-way ANOVA followed by a post hoc Bonferroni multiple comparison test).

\section{Nausea and Emesis}

Nausea and vomiting (emesis) are highly complex processes in terms of both anatomy and physiology [36]. Although protective against orally ingested potentially damaging materials, nausea and vomiting are also frequent and unpleasant symptoms of many diseases, as well as side effects of medications used in the treatment of pain (e.g. opiates), cancer (chemotherapeutics), viral infections (interferon, antiviral drugs) and other conditions. The introduction of $5-\mathrm{HT}_{3}$ antagonists, together with the corticoid dexamethasone and aprepitant (a neurokinin 1 receptor antagonist), has largely controlled chemotherapy-induced acute vomiting. However, nausea is often reported as more distressing than vomiting [37]. Nausea, as well as delayed and anticipatory vomiting associated with chemotherapy, is not well controlled with the current anti-emetic medication, and CBs have been proposed as an attractive alternative.

Regulation of nausea and vomiting by CBs has been recently reviewed [38]. Different CBs (THC and nabilone, 
its synthetic analogue) and $\mathrm{CB}$ extracts (containing both THC and CBD) have proved to be effective anti-emetics in humans $[39,40]$. Moreover, CBs exert antinauseant effects [41]. Nevertheless, new, systematic clinical studies, particularly those comparing CBs and other treatments, are still needed [38].

Since rats and mice do not vomit, it is necessary to use other models of emesis in order to evaluate the anti-emetic potential of drug therapies. CBs inhibit emesis in animal models (e.g. ferrets; least shrews, Cryptotis parva; house musk shrews, Suncus murinus) of acute cisplatin-, morphine- and radiation-induced emesis, as well as in cisplatin-induced delayed emesis, and in motion sickness $[11,36,38]$. Furthermore, CBs attenuate characteristic non-emetic responses (conditioned gaping, conditioned taste aversion) to emetic stimuli in rodents [38].

THC as well as anandamide, 2-AG and the blockers of their degradation all have been shown to exert anti-emetic effects, although some dose and species dependency might exist [38]. CB1 [42], TRPV1 [43] and possibly CB2 [44] receptors, located in areas of the brain involved in emesis, have mediated the anti-emetic effect of CBs. CB1 antagonists may produce emesis on its own or facilitate that induced by emetic stimuli [42]. Peripheral sites might also be involved in THC anti-emetic effect, particularly when used at high doses [45]. CBs may act at CB1 presynaptic receptors to inhibit the release of newly synthesized 5-HT [45], and rimonabant increased brain 5-HT levels and turnover at doses that induce vomiting in the shrew [46]. Interestingly, the combination of low doses of CBs and $5-\mathrm{HT}_{3}$ antagonists was more efficacious than any of the drugs alone to control emesis in the least shrew [47].

Nausea is more resistant to effective treatment with anti-emetic agents than is vomiting [37] and therefore remains a significant problem in chemotherapy treatment and as a side effect from other pharmacological therapies, such as antidepressants. Although the vomiting response is absent in the rat, the detection mechanism of nausea is present as suggested by central c-fos activation patterns [48]. Thus, the effects of CBs on conditioned taste avoidance and, more selectively, conditioned gaping, have been used to measure nausea in these rodents [38]. Rats display disgust reactions (including gaping, chin rubbing and paw treading) when they are intra-orally infused with a bittertasting quinine solution. Rats also display this disgust pattern when infused with a sweet-tasting solution (that normally elicits hedonic reactions of tongue protrusions) that has previously been paired with a drug that produces vomiting (such as $\mathrm{LiCl}$ or cyclophosphamide) in species capable of vomiting. Only drugs with emetic properties produce this conditioned disgust reaction when paired with a taste. Parker et al. [38] have suggested that, in fact, gape in the rat represents an 'incipient vomiting response', and muscular movements involved in the gaping response mimic those seen in species capable of vomiting. Using this model, THC, HU-210 and the FAAH blocker URB597 alone or in combination with anandamide suppressed conditioned gaping reactions, via $\mathrm{CB} 1$ receptor activation (review in Parker et al. [38]). The inverse agonist AM251 (but not different neutral antagonists) produced conditioned gaping at high doses, an effect that may be mediated peripherally, since it was evident after systemic but not intracerebroventricular administration [38, 49].

Another characteristic non-emetic response to emetic stimuli displayed by rodents is the ingestion of non-nutritive substances, a feeding behaviour known as pica. This behaviour is prevented by treatment with classical antiemetics [37]. However, in our laboratory, pica (kaolin intake) induced in the rat by acute and repeated (5 intraperitoneal injections, 1/week) cisplatin administration was not prevented by concomitant WIN administration [50]. This somehow unexpected finding made us study the modifications induced by acute and repeated cisplatin on GI motility by radiographic means and found that: pica and delayed gastric emptying were temporally related [51]; the repeated administration of cisplatin induced a parallel increase in both pica and delayed gastric emptying [52]. As mentioned above, upon WIN intermittent administration (4 intraperitoneal injections, 1/week), which was the pattern of administration applied in the mentioned pica study [50], delayed gastric emptying was also intensified [31]. It is likely that the lack of effect of WIN on pica behaviour induced by cisplatin has something to do with the fact that both drugs delayed gastric emptying in the rat, and likely added their effects on the GI tract. Experiments are currently under way to ascertain this.

Anecdotal evidence suggests that THC alleviates anticipatory nausea in chemotherapy patients. Suncus murinus displays conditioned retching when returned to a chamber previously paired with a dose of $\mathrm{LiCl}$ that produced vomiting, and this was suppressed by pretreatment with THC but not by ondansetron [53]. Rats also display conditioned gaping reactions when re-exposed to a context previously paired with LiCl-induced nausea, and this behaviour was prevented by the FAAH inhibitor URB597 [54].

In spite of the different evidences on the beneficial effects of CBs (including those obtained in experimental models), their therapeutic use in emesis remains unsatisfactory due to the risk of severe central side effects (anxiety, depression, hallucinations), which in experimental 
animals take the form of the so-called CB tetrad (i.e. analgesia, catalepsy, hypothermia and hypolocomotion). This might be avoided by the use of low doses of the CBs, but these low doses might obviously not display the desired effects on GI motility (as examples, the effect of different doses of WIN on both the CB tetrad and GI motor function measured in the rat are described in Abalo et al. [29-31]). Alternatively, other ligands devoid of these effects might be useful. In these regards, CBD, a major, non-psychotropic phytocannabinoid with low affinity for the CB1 and CB2 receptors, has a biphasic effect on emesis, with high doses potentiating and low doses inhibiting toxin-induced vomiting and anticipatory retching in S. murinus (review in Parker et al. [38]). CBD might act as an indirect agonist on the $5-\mathrm{HT}_{1 \mathrm{~A}}$ autoreceptors, to reduce the availability of 5-HT [55]. CBD also suppressed LiCl-induced gaping (nausea) by activation of somatodendritic autoreceptors located in the dorsal raphe nucleus, reducing the release of forebrain 5-HT [56]. Conditioned retching in S. murinus and conditioned gaping in the rat induced by the context (signs of anticipatory vomiting and nausea, respectively) were also reduced by CBD $[53,56]$. All these data suggest that CBD might be a useful non-psychotropic $\mathrm{CB}$ alternative to control nausea and emesis in humans too; to our knowledge, it has not been tested on its own for this, but the effects are positive when combined with THC [40].

Although generally considered efficient anti-emetics, CBs may induce paroxysmal vomiting (CB hyperemesis syndrome), which has been noticed in patients with a history of chronic cannabis use [57-59]. There is currently no convincing explanation for this paradox. The peculiar effects of chronic (daily and intermittent) CB administration on gastric motor function found in the rat $[29,31]$ suggest that repeated administration of CBs might trigger plastic changes in expression of $\mathrm{CB}$ receptors within the stomach wall (or other sites). Whether or not this contributes to the $\mathrm{CB}$ hyperemesis syndrome needs to be elucidated. Whatever the case may be, it is likely that some patients under chronic CB therapy might experience gastric discomfort and even hyperemesis, which might constitute a caveat to $\mathrm{CB}$ therapeutic use.

\section{Altered Intestinal Motility}

As mentioned above, Cannabis has been empirically used for centuries to treat diarrhoeas. On the other hand, when the CB1 antagonist rimonabant was introduced as an anorexigenic drug, it caused diarrhoea in some obese patients [60]. Modifying the $\mathrm{CB}$ tone in the gut has therefore important therapeutic implications.

Cannabinoids and Gastrointestinal Motility
Hypermotility: Inflammatory Bowel Syndrome and Inflammatory Bowel Disease

Inflammatory bowel syndrome (IBS) is a functional disorder characterized by abdominal discomfort, bloating, altered bowel habits and the absence of organic abnormalities due to biological and psychosocial factors, including alterations in gut motility, disturbances in gut-brain signalling, visceral hypersensitivity and bacterial overgrowth. IBS presents in three different forms: diarrhoea-predominant (D-IBS), constipation-predominant (C-IBS) or mixed (episodes of either diarrhoea or constipation). The role of the endocannabinoid system in the pathophysiology and treatment of IBS has been reviewed elsewhere [61]. Due to their effects on motility and secretion, CB1 agonists might be useful to treat D-IBS, whereas CB1 antagonists could be useful to treat C-IBS. Activation of CB2 receptors, which are overexpressed in the gut under inflammatory conditions [14], might also be useful to treat D-IBS. On the other hand, FAAH blockers, which both raise anandamide levels and act as TRPV1 antagonists, could be an interesting option for treatment of visceral hypersensitivity [3]. Polymorphisms in the $\mathrm{CB} 1$ receptor (CNR1) or FAAH genes might be involved in the development of IBS, although evidence is still limited and large clinical trials using validated clinical end points are required [62].

Inflammatory bowel disease (IBD) is a chronic and relapsing inflammation of the GI tract, which comprises both Crohn's disease and ulcerative colitis. These are multifactorial diseases caused by an uncontrolled immune response to microbial antigens. Anecdotal reports suggest that some IBD patients experience relief when smoking marijuana [63]. Accordingly, a questionnairebased study at Mount Sinai Hospital showed that cannabis use is common amongst patients with IBD for symptom relief, particularly amongst those patients with a history of abdominal surgery, chronic abdominal pain and/ or a low quality of life index [64]. As in the case of IBS, polymorphisms of FAAH and CNR1 might be involved in the genetic susceptibility to IBD $[65,66]$.

Different stimuli (cholera toxin; dinitrobenzene sulphonic acid; trinitrobenzene sulphonic acid; mustard oil; croton oil; dextran sulphate) have been used to induce colitis in rodents. In these models, both CB1 and CB2 receptor activation may reduce hypermotility associated with gut inflammation and/or immune activation, as well as decreasing pain, intestinal fluid volume and inflammation (review in Izzo and Sharkey [11] and Izzo and Camilleri [16]). A beneficial effect has been shown for THC, CB1 and CB2 agonists and inhibitors of anandamide or 2-AG degradation/reuptake [11, 16, 67]. Acti- 
vation of not only CB1 [68], but also CB2 receptors [14] reduced electrically evoked contractions of muscle preparations from inflamed gut. Inhibitors of anandamide reuptake or enzymatic hydrolysis, which increase intestinal anandamide levels, reduced dinitrobenzene sulphonic acid-induced colonic inflammation in wild-type, but not CB1 or CB2 receptor-deficient mice [69]. Mutated mice lacking $\mathrm{CB} 2$ receptors were more sensitive to the inflammatory effects of trinitrobenzene sulphonic acid $[69,70]$. FAAH-deficient mice, which are expected to have higher levels of anandamide, showed significant protection against intestinal inflammation due to dinitrobenzene sulphonic acid [68] or endotoxin [71] administration.

Several phytocannabinoids have been tested in models of colitis. Interestingly, these compounds can affect both the activity and the expression of TRPV1-4 channels [72]. CBD has reduced colonic inflammation in the mouse after intraperitoneal and rectal but not oral administration [73]. Another non-psychotropic phytocannabinoid, cannabichromene, which inhibits endocannabinoid inactivation and activates the transient receptor potential ankyrin 1, normalized croton oil-induced hypermotility in vivo and reduced electrically but not acetylcholine-induced ileal contractions in vitro, in a $\mathrm{CB}$ receptor- and transient receptor potential ankyrin 1independent manner [74]. In addition, it reduced the expression of several TRPV subtypes in different GI regions of croton oil-treated mice [72].

Hypomotility: Paralytic Ileus

Paralytic ileus is a GI disorder characterized by decreased intestinal motility following peritonitis, surgery or other noxious situations. The intraperitoneal administration of acetic acid in mice reduced intestinal motility, and this occurred together with an increase in anandamide levels and overexpression of CB1 receptors in the myenteric plexus; these effects were alleviated by rimonabant, but not by $\mathrm{CB} 2$ receptor inactivation, and were worsened by VDM11, an inhibitor of anandamide cellular uptake [75]. In contrast, in a model of septic ileus in the rat, inactivation of either $\mathrm{CB} 1$ or $\mathrm{CB} 2$ receptors led to normalization of motility, spontaneous jejunal myoelectrical activity and levels of interleukin 6 [76]. Thus, the release of endogenous CBs might be involved in the development of paralytic ileus, and different strategies aimed at normalizing endocannabinoid levels might be therapeutically useful in these conditions. In addition, CBD was also beneficial in a model of ileus in mice [77], maybe via a reduction in nitric oxide production [78].

\section{Conclusions}

From the existing data (obtained in vivo both in humans and in animal models, as well as from isolated GI preparations), it is clear that CBs profoundly alter GI motor function and that this, mediated via different mechanisms of action, may be therapeutically exploited. So far, two of the three commercially available CB-based medicines (Marinol and Cesamet) are used for GI-related alterations. Experimental data demonstrate that different $\mathrm{CB}$ agonists and antagonists, as well as drugs aimed at modifying the endocannabinoid levels and non-psychotropic phytocannabinoids, do have therapeutic potential that will possibly increase the number of indications for both GI and non-GI diseases. Several limitations will have to be overcome by the candidate compounds before they can be introduced for therapeutic use. Ideally, these should be devoid of central side effects (peripherally restricted or non-psychotropic drugs) and should not develop tolerance or induce hyperemesis or GI discomfort upon chronic administration. Time will tell whether these characteristics are achieved by any CB-based strategy.

\section{Acknowledgements}

This work was supported by the Spanish Ministry of Education and Science (SAF2009-12422-C02-01), the Comunidad de Madrid (S-SAL/0261/2006 and S2010/BMD-2308) and the Department of Pharmacology and Nutrition is Unidad Asociada $\mathrm{I}+\mathrm{D}+\mathrm{i}$ del Consejo Superior de Investigaciones Científicas (CSIC).

References

1 Izzo AA, Coutts AA: Cannabinoids and the digestive tract. Handb Exp Pharmacol 2005; 168:573-598.

2 Izzo AA, Borrelli F, Capasso R, Di Marzo V, Mechoulam R: Non-psychotropic plant cannabinoids: new therapeutic opportunities from an ancient herb. Trends Pharmacol Sci 2009;30:515-527.

3 Schicho R, Storr M: Alternative targets within the endocannabinoid system for future treatment of gastrointestinal diseases. Can J Gastroenterol 2011;25:377-383.

4 Di Marzo V, Fontana A: Anandamide, an endogenous cannabinomimetic eicosanoid: 'killing two birds with one stone'. Prostaglandins Leukot Essent Fatty Acids 1995;53: $1-11$.

5 Di Marzo V: The endocannabinoid system: its general strategy of action, tools for its pharmacological manipulation and potential therapeutic exploitation. Pharmacol Res 2009;60:77-84

Abalo/Vera/López-Pérez/

Martínez-Villaluenga/Martín-Fontelles 
-6 Pertwee RG, Howlett AC, Abood ME, Alexander SP, Di Marzo V, Elphick MR, Greasley PJ, Hansen HS, Kunos G, Mackie K, Mechoulam R, Ross RA: International Union of Basic and Clinical Pharmacology. LXXIX. Cannabinoid receptors and their ligands: beyond $\mathrm{CB}_{1}$ and $\mathrm{CB}_{2}$. Pharmacol Rev 2010;62:588-631.

7 Di Marzo V, Fontana A, Cadas H, Schinelli S, Cimino G, Schwartz JC, Piomelli D: Formation and inactivation of endogenous cannabinoid anandamide in central neurons. Nature 1994;372:686-691.

8 Glaser ST, Kaczocha M, Deutsch DG: Anandamide transport: a critical review. Life Sci 2005;77:1584-1604.

9 Duncan M, Davison JS, Sharkey KA: Review article: endocannabinoids and their receptors in the enteric nervous system. Aliment Pharmacol Ther 2005;22:667-683.

- 10 Aviello G, Romano B, Izzo AA: Cannabinoids and gastrointestinal motility: animal and human studies. Eur Rev Med Pharmacol Sci 2008;12(suppl 1):81-93.

$\checkmark 11$ Izzo AA, Sharkey KA: Cannabinoids and the gut: new developments and emerging concepts. Pharmacol Ther 2010;126:21-38

-12 Di Marzo V, Piscitelli F: Gut feelings about the endocannabinoid system. Neurogastroenterol Motil 2011;23:391-398.

$\checkmark 13$ Wright KL, Duncan M, Sharkey KA: Cannabinoid CB2 receptors in the gastrointestinal tract: a regulatory system in states of inflammation. Br J Pharmacol 2008;153:263270 .

-14 Duncan M, Thomas AD, Cluny NL, Patel A, Patel KD, Lutz B, Piomelli D, Alexander SP, Sharkey KA: Distribution and function of monoacylglycerol lipase in the gastrointestinal tract. Am J Physiol Gastrointest Liver Physiol 2008;295:G1255-G1265.

-15 Prestifilippo JP, Fernández-Solari J, de la Cal C, Iribarne M, Suburo AM, Rettori V, McCann SM, Elverdin JC: Inhibition of salivary secretion by activation of cannabinoid receptors. Exp Biol Med (Maywood) 2006;231: 1421-1429.

-16 Izzo AA, Camilleri M: Cannabinoids in intestinal inflammation and cancer. Pharmacol Res 2009;60:117-125.

$\checkmark 17$ Drew WG, Miller LL, Wikler A: Effect of 9-THC on the open-field activity of the rat. Psychopharmacologia 1972;23:289-299.

-18 Chesher GB, Dahl CJ, Everingham M, Jackson DM, Marchant-Williams H, Starmer GA: The effect of cannabinoids on intestinal motility and their antinociceptive effect in mice. Br J Pharmacol 1973;49:588-594.

19 Gill EW, Paton WD, Pertwee RG: Preliminary experiments on the chemistry and pharmacology of cannabis. Nature 1970;228: 134-136.

20 Roth SH: Stereospecific presynaptic inhibitory effect of delta9-tetrahydrocannabinol on cholinergic transmission in the myenteric plexus of the guinea pig. Can J Physiol Pharmacol 1978;56:968-975.
21 Pertwee RG: Cannabinoids and the gastrointestinal tract. Gut 2001;48:859-867.

22 Pertwee RG, Fernando SR, Nash JE, Coutts AA: Further evidence for the presence of cannabinoid CB1 receptors in guinea-pig small intestine. Br J Pharmacol 1996;118: 2199-2205.

23 López-Redondo F, Lees GM, Pertwee RG: Effects of cannabinoid receptor ligands on electrophysiological properties of myenteric neurones of the guinea-pig ileum. Br J Pharmacol 1997;122:330-334.

-24 Coutts AA, Irving AJ, Mackie K, Pertwee RG, Anavi-Goffer S: Localisation of cannabinoid $\mathrm{CB}(1)$ receptor immunoreactivity in the guinea pig and rat myenteric plexus. J Comp Neurol 2002;448:410-422.

25 Grider JR, Mahavadi S, Li Y, Qiao LY, Kuemmerle JF, Murthy KS, Martin BR: Modulation of motor and sensory pathways of the peristaltic reflex by cannabinoids. Am J Physiol Gastrointest Liver Physiol 2009; 297:G539-G549.

26 Galligan JJ: Cannabinoid signalling in the enteric nervous system. Neurogastroenterol Motil 2009;21:899-902.

-27 Boesmans W, Ameloot K, van den Abbeel V, Tack J, Vanden Berghe P: Cannabinoid receptor 1 signalling dampens activity and mitochondrial transport in networks of enteric neurones. Neurogastroenterol Motil 2009, 21:958-e77.

28 Hons IM, Storr MA, Mackie K, Lutz B, Pittman QJ, Mawe GM, Sharkey KA: Plasticity of mouse enteric synapses mediated through endocannabinoid and purinergic signaling. Neurogastroenterol Motil 2012;24:e113e124.

29 Abalo R, Cabezos PA, López-Miranda V, Vera G, González C, Castillo M, FernándezPujol R, Martín MI: Selective lack of tolerance to delayed gastric emptying after daily administration of WIN 55,212-2 in the rat. Neurogastroenterol Motil 2009;21:1002-e80

- 30 Abalo R, Cabezos PA, Vera G, FernándezPujol R, Martín MI: The cannabinoid antagonist SR144528 enhances the acute effect of WIN 55,212-2 on gastrointestinal motility in the rat. Neurogastroenterol Motil 2010;22: 694-e206.

-31 Abalo R, Cabezos PA, Vera G, López-Miranda V, Herradón E, Martín-Fontelles MI: Cannabinoid-induced delayed gastric emptying is selectively increased upon intermittent administration in the rat: role of CB1 receptors. Neurogastroenterol Motil 2011;23: 457-467, e177.

\32 Perry RL, Williams JF, Carrig CB, Kaneene JB, Schillhorn van Veen TW: Radiologic evaluation of the liver and gastrointestinal tract in rats infected with Taenia taeniaefor mis. Am J Vet Res 1994;55:1120-1126.

33 Beaumont H, Jensen J, Carlsson A, Ruth M, Lehmann A, Boeckxstaens G: Effect of delta9-tetrahydrocannabinol, a cannabinoid receptor agonist, on the triggering of transient lower oesophageal sphincter relax- ations in dogs and humans. Br J Pharmacol 2009; 156:153-162

$>34$ Rohof WO, Aronica E, Beaumont H, Troost D, Boeckxstaens GE: Localization of mGluR5, GABA(B), GABA(A), and cannabinoid receptors on the vago-vagal reflex pathway responsible for transient lower esophageal sphincter relaxation in humans: an immunohistochemical study. Neurogastroenterol Motil 2012;24:383-e173.

$\checkmark 35$ Cui YY, D’Agostino B, Risse PA, Marrocco G, Naline E, Zhang Y, Chen HZ, Finance O, Rinaldi-Carmona M, Rossi F, Advenier C: Cannabinoid $\mathrm{CB}(2)$ receptor activation prevents bronchoconstriction and airway oedema in a model of gastro-oesophageal reflux. Eur J Pharmacol 2007;573:206-213.

\36 Holmes AM, Rudd JA, Tattersall FD, Aziz Q, Andrews PL: Opportunities for the replacement of animals in the study of nausea and vomiting. Br J Pharmacol 2009;157:865-880.

37 Andrews PL, Horn CC: Signals for nausea and emesis: implications for models of upper gastrointestinal diseases. Auton Neurosci 2006;125:100-115.

>38 Parker LA, Rock EM, Limebeer CL: Regulation of nausea and vomiting by cannabinoids. Br J Pharmacol 2011;163:1411-1422.

39 Tramèr MR, Carroll D, Campbell FA, Reynolds DJ, Moore RA, McQuay HJ: Cannabinoids for control of chemotherapy induced nausea and vomiting: quantitative systematic review. BMJ 2001;323:16-21.

40 Duran M, Pérez E, Abanades S, Vidal X, Saura C, Majem M, Arriola E, Rabanal M, Pastor A, Farré M, Rams N, Laporte JR, Capellà D: Preliminary efficacy and safety of an oromucosal standardized cannabis extract in chemotherapy-induced nausea and vomiting. Br J Clin Pharmacol 2010;70:656-663.

$\checkmark 41$ Costiniuk CT, Mills E, Cooper CL: Evaluation of oral cannabinoid-containing medications for the management of interferon and ribavirin-induced anorexia, nausea and weight loss in patients treated for chronic hepatitis C virus. Can J Gastroenterol 2008; 22:376-380.

42 Van Sickle MD, Oland LD, Ho W, Hillard CJ, Mackie K, Davison JS, Sharkey KA: Cannabinoids inhibit emesis through CB1 receptors in the brainstem of the ferret. Gastroenterology 2001;121:767-774.

43 Sharkey KA, Cristino L, Oland LD, Van Sickle MD, Starowicz K, Pittman QJ, Guglielmotti V, Davison JS, Di Marzo V: Arvanil, anandamide and $\mathrm{N}$-arachidonoyl-dopamine (NADA) inhibit emesis through cannabinoid CB1 and vanilloid TRPV1 receptors in the ferret. Eur J Neurosci 2007;25:27732782.

44 Van Sickle MD, Duncan M, Kingsley PJ, Mouihate A, Urbani P, Mackie K, Stella N, Makriyannis A, Piomelli D, Davison JS, Marnett LJ, Di Marzo V, Pittman QJ, Patel KD, Sharkey KA: Identification and functional characterization of brainstem cannabinoid CB2 receptors. Science 2005;310:329-332. 
45 Darmani NA, Johnson JC: Central and peripheral mechanisms contribute to the antiemetic actions of delta-9-tetrahydrocannabinol against 5-hydroxytryptophan-induced emesis. Eur J Pharmacol 2004;488:201-212.

-46 Darmani NA, Janoyan JJ, Kumar N, Crim JL: Behaviorally active doses of the $\mathrm{CB} 1$ receptor antagonist SR 141716A increase brain serotonin and dopamine levels and turnover. Pharmacol Biochem Behav 2003;75:777-787.

-47 Wang Y, Ray AP, McClanahan BA, Darmani NA: The antiemetic interaction of D9-tetrahydrocannabinol when combined with tropisetron or dexamethasone in the least shrew. Pharmacol Biochem Behav 2009;91: 367-373.

48 Billig I, Yates BJ, Rinaman L: Plasma hormone levels and central c-Fos expression in ferrets after systemic administration of cholecystokinin. Am J Physiol Regul Integr Comp Physiol 2001;281:R1243-R1255.

49 Limebeer CL, Vemuri VK, Bedard H, Lang ST, Ossenkopp KP, Makriyannis A, Parker LA: Inverse agonism of $\mathrm{CB} 1$ receptors potentiates LiCl-induced nausea: evidence from the conditioned gaping model in rats. $\mathrm{Br} \mathrm{J}$ Pharmacol 2010;161:336-349.

- 50 Vera G, Chiarlone A, Cabezos PA, Pascual D, Martín MI, Abalo R: WIN 55,212-2 prevents mechanical allodynia but not alterations in feeding behaviour induced by chronic cisplatin in the rat. Life Sci 2007;81:468-479.

-51 Cabezos PA, Vera G, Castillo M, FernándezPujol R, Martín MI, Abalo R: Radiological study of gastrointestinal motor activity after acute cisplatin in the rat. Temporal relationship with pica. Auton Neurosci 2008; 141:5465.

- 52 Cabezos PA, Vera G, Martín-Fontelles MI, Fernández-Pujol R, Abalo R: Cisplatin-induced gastrointestinal dysmotility is aggravated after chronic administration in the rat. Comparison with pica. Neurogastroenterol Motil 2010;22:797-805, e224-e225.

- 53 Parker LA, Kwiatkowska M, Mechoulam R: Delta-9-tetrahydrocannabinol and cannabidiol, but not ondansetron, interfere with conditioned retching reactions elicited by a lithium-paired context in Suncus murinus: an animal model of anticipatory nausea and vomiting. Physiol Behav 2006;87:61-71.

54 Rock EM, Limebeer CL, Mechoulam R, Piomelli D, Parker LA: The effect of cannabidiol and URB597 on conditioned gaping (a model of nausea) elicited by a lithium-paired context in the rat. Psychopharmacol 2008; 196 : 389-395.

55 Russo EB, Burnett A, Hall B, Parker KK: Agonist properties of cannabidiol at 5-HT1a receptors. Neurochem Res 2005;30:1037-1043.
56 Rock EM, Bolognini D, Limebeer CL, Cascio MG, Anavi-Goffer S, Fletcher PJ, Mechoulam R, Pertwee RG, Parker LA: Cannabidiol, a non-psychotropic component of cannabis, attenuates vomiting and nausea-like behaviour via indirect agonism of 5-HT(1A) somatodendritic autoreceptors in the dorsal raphe nucleus. Br J Pharmacol 2011, DOI: 10.1111/j.1476-5381.2011.01621.

57 Allen JH, de Moore GM, Heddle R, Twartz JC: Cannabinoid hyperemesis: cyclical hyperemesis in association with chronic cannabis abuse. Gut 2004;53:1566-1570.

58 Galli JA, Sawaya RA, Friedenberg FK: Cannabinoid hyperemesis syndrome. Curr Drug Abuse Rev 2011;4:241-249.

59 Choung RS, Locke GR 3rd, Lee RM, Schleck CD, Zinsmeister AR, Talley NJ: Cyclic vomiting syndrome and functional vomiting in adults: association with cannabinoid use in males. Neurogastroenterol Motil 2012;24: 20-26, e1.

60 Després JP: Pleiotropic effects of rimonabant: clinical implications. Curr Pharm Des 2009;15:553-570.

61 Storr MA, Yüce B, Andrews CN, Sharkey KA: The role of the endocannabinoid system in the pathophysiology and treatment of irritable bowel syndrome. Neurogastroenterol Motil 2008:20:857-868.

62 Camilleri M, Katzka DA: Genetic epidemiology and pharmacogenetics in irritable bowel syndrome. Am J Physiol Gastrointest Liver Physiol 2012, E-pub ahead of print.

63 Di Marzo V, Izzo AA: Endocannabinoid overactivity and intestinal inflammation. Gut 2006;55:1373-1376.

64 Lal S, Prasad N, Ryan M, Tangri S, Silverberg MS, Gordon A, Steinhart H: Cannabis use amongst patients with inflammatory bowel disease. Eur J Gastroenterol Hepatol 2011; 23:891-896.

-65 Camilleri M, Carlson P, McKinzie S, Grudell A, Busciglio I, Burton D, Baxter K, Ryks M, Zinsmeister AR: Genetic variation in endocannabinoid metabolism, gastrointestinal motility, and sensation. Am J Physiol Gastrointest Liver Physiol 2008;294:G13-G19.

66 Storr M, Emmerdinger D, Diegelmann J, Pfennig S, Ochsenkühn T, Göke B, Lohse P, Brand S: The cannabinoid 1 receptor (CNR1) 1359 G/A polymorphism modulates susceptibility to ulcerative colitis and the phenotype in Crohn's disease. PLoS One 2010;5:e9453.

67 Alhouayek M, Lambert DM, Delzenne NM, Cani PD, Muccioli GG: Increasing endogenous 2-arachidonoylglycerol levels counteracts colitis and related systemic inflammation. FASEB J 2011;25:2711-2721.

68 Massa F, Marsicano G, Hermann H, Cannich A, Monory K, Cravatt BF, Ferri GL, Sibaev A, Storr M, Lutz B: The endogenous cannabinoid system protects against colonic inflammation. J Clin Invest 2004;113:1202-1209.
-69 Storr MA, Keenan CM, Emmerdinger D, Zhang H, Yüce B, Sibaev A, Massa F, Buckley NE, Lutz B, Göke B, Brand S, Patel KD, Sharkey KA: Targeting endocannabinoid degradation protects against experimental colitis in mice: involvement of $\mathrm{CB} 1$ and $\mathrm{CB} 2$ receptors. J Mol Med (Berl) 2008;86:925-936.

-70 Storr MA, Keenan CM, Zhang H, Patel KD, Makriyannis A, Sharkey KA: Activation of the cannabinoid 2 receptor $(\mathrm{CB} 2)$ protects against experimental colitis. Inflamm Bowel Dis 2009;15:1678-1685.

-71 Bashashati M, Storr MA, Nikas SP, Wood JT, Godlewski G, Liu J, Ho W, Keenan CM, Zhang H, Alapafuja SO, Cravatt BF, Lutz B, Mackie K, Kunos G, Patel KD, Makriyannis A, Davison JS, Sharkey KA: Inhibiting fatty acid amide hydrolase normalizes endotoxininduced enhanced gastrointestinal motility in mice. Br J Pharmacol 2012;165:1556-1571.

72 De Petrocellis L, Orlando P, Moriello AS, Aviello G, Stott C, Izzo AA, Di Marzo V: Cannabinoid actions at TRPV channels: effects on TRPV 3 and TRPV4 and their potential relevance to gastrointestinal inflammation. Acta Physiol (Oxf) 2012;204:255-266.

73 Schicho R, Storr M: Topical and systemic cannabidiol improves trinitrobenzene sulfonic acid colitis in mice. Pharmacology 2012;89:149-155.

74 Izzo AA, Capasso R, Aviello G, Borrelli F, Romano B, Piscitelli F, Gallo L, Capasso F, Orlando P, Di Marzo V: Inhibitory effect of cannabichromene, a major non-psychotropic cannabinoid extracted from Cannabis sativa, on inflammation-induced hypermotility in mice. Br J Pharmacol 2012, DOI: 10.1111/j.1476-5381.2012.01879.x.

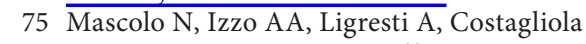
A, Pinto L, Cascio MG, Maffia P, Cecio A, Capasso F, Di Marzo V: The endocannabinoid system and the molecular basis of paralytic ileus in mice. FASEB J 2002;16:19731975.

76 Li YY, Li YN, Ni JB, Chen CJ, Lv S, Chai SY, Wu RH, Yüce B, Storr M: Involvement of cannabinoid-1 and cannabinoid-2 receptors in septic ileus. Neurogastroenterol Motil 2010;22:350-e88.

77 Lin XH, Yuece B, Li YY, Feng YJ, Feng JY, Yu LY, Li K, Li YN, Storr M: A novel CB receptor GPR55 and its ligands are involved in regulation of gut movement in rodents. Neurogastroenterol Motil 2011;23:862-e342.

78 Esposito G, De Filippis D, Maiuri MC, De Stefano D, Carnuccio R, Iuvone T: Cannabidiol inhibits inducible nitric oxide synthase protein expression and nitric oxide production in beta-amyloid stimulated PC12 neurons through p38 MAP kinase and NF-kappaB involvement. Neurosci Lett 2006;399: 91-95. 